\title{
OS TRIBUNAIS PENAIS INTERNACIONAIS \\ E SUA CONTRIBUIÇÃO PARA O \\ DESENVOLVIMENTO DOS DIREITOS \\ HUMANOS: DE NUREMBERG AO TRIBUNAL \\ PENAL INTERNACIONAL (TPI)
}

\author{
Barbara Mourão Sachett*
}

\section{RESUMO}

O objetivo do presente artigo é analisar a partir dos tratados sobre o tema, da doutrina e da jurisprudência, como os julgamentos de Nuremberg e a condenação dos criminosos de guerra, pelos crimes contra a humanidade, de guerra e contra a paz, previstos no Acordo de Londres, de 1945, lançaram as bases, décadas mais tarde, para a constituição do Tribunal Penal Internacional (TPI).

Palavras-chave: Nuremberg. Ad Hoc. Direitos Humanos.TPI.

\section{ABSTRACT}

The purpose of this article is to analyze, starting from the treatises on the subject, the doctrine and jurisprudence, as the Nuremberg trials and sentencing of war criminals, crimes against humanity, war crimes and crimes against peace, under the Agreement London, in 1945, laid the foundation, decades later, to the establishment of the International Criminal Court (ICC).

Key-words: Nuremberg. Ad hoc. Human Rights. CCI.

* Graduada em Direito pela Universidade Estadual Paulista - Júlio de Mesquita Filho, UNESP-Campus-Franca (1997) e Mestre em Direito pela mesma Universidade (2002). Atualmente, é professora da Universidade Metodista de São Paulo, onde leciona nos cursos de Direito, Ciências Contábeis e Administração. Tem experiência profissional na área de Direito, com ênfase em Direito Internacional. Advogada militante nas áreas de Direito Internacional, Direito de Família e Empresarial. 


\section{INTRODUÇÃO}

O Tribunal Penal Internacional, criado em 1998, por meio do Estatuto de Roma, tem competência para julgar os crimes de violações de direitos humanos.

A evolução dos direitos humanos se deu por meio de gerações e com a própria evolução da humanidade.

A criação dos tribunais ad hoc tiveram uma grande contribuição nessa evolução: o primeiro desses tribunais, em que pesem as críticas, foi o Tribunal de Nuremberg, criado no pós guerra para julgar os criminosos nazistas, e que lançou as bases para as cortes dos anos 90 e para o Tribunal Penal Internacional (TPI) .

Nos anos 90 foram criadas as cortes ad hoc: o Tribunal Penal Internacional para Ruanda e o Tribunal Penal Internacional para a antiga Iugoslávia, que também lançaram as bases para a criação de uma corte penal permanente: o Tribunal Penal Internacional (TPI).

1. Internacionalização dos direitos humanos e a justiça internacional

A evolução dos direitos humanos se dá com a própria evolução da sociedade humana, e principalmente com o desenvolvimento da fé monoteísta:

A grande contribuição do povo da Bíblia à humanidade, uma das maiores, aliás, de toda a História, foi a ideia da criação do mundo por um Deus único e transcendente. Os deuses antigos, de certa forma, faziam parte do mundo, como super homens, com as mesmas paixões e defeitos do ser humano. Iahweh, muito ao contrário, como criador de tudo o que existe, é anterior e superior ao mundo. (COMPARATO, 1999, p.1).

Contudo, foi somente no século XVIII que os direitos humanos, a partir dos ideais que basearam a Revolução Francesa, em 1789, e a Independência Americana, em 1776, passaram a constituir um corpo de direitos sistematizados e 
constantes, respectivamente, da Declaração dos Direitos do Homem e do Cidadão, de 1789, e da Declaração de Independência Americana (da Virginia), de 1776.

O artigo 1.o da Declaração dos Direitos do Homem e do Cidadão, de 1789, reza que: Os homens nascem e permanecem livres e iguais em direitos.

É o primado dos princípios basilares da Revolução Francesa: liberdade e igualdade. O terceiro princípio; fraternidade, a exigência de uma organização solidária da vida em comum, frise-se, somente teve seu reconhecimento formal muito tempo depois, com a Declaração Universal dos Direitos Humanos, de 1948, sob os auspícios da ONU.

Essas declarações estão intimamente ligadas, no século XIX, à afirmação e ao reconhecimento de novos direitos humanos de cunho econômicos e sociais nas Constituições de Weimar, de 1919, e na Constituição do México, de 1917, ou seja, pela primeira vez, principios fundamentais de direitos humanos aparecem, sistematicamente, por meio de garantias nos direitos internos, mais precisamente, nas já citadas Constituições.

A garantia dos direitos fundamentais e garantias individuais, por meio de direitos trabalhistas e sociais, de uma maneira geral, nas Constituições, foram responsáveis, em alguma medida, por mais um passo na evolução dos direitos humanos na sociedade internacional, por meio da internacionalização.

Conforme Fábio Konder Comparato, "A primeira fase de internacionalização dos direitos humanos teve início da segunda metade do século XIX e teve fim com a Segunda Guerra Mundial, manifestando-se basicamente em três setores: o direito humanitário, a luta contra a escravidão e a regulação dos direitos do trabalhador assalariado" (COMPARATO, 1999, p.42).

Durante a sessão de 16 de fevereiro de 1946 do Conse1ho Econômico e Social das Nações Unidas, foi decidido que a Comissão de Direitos Humanos, que seria criada, deveria 
desenvolver seus trabalhos em três etapas. Na primeira, que interessa mais a esse trabalho, deveria elaborar uma declaração de direitos humanos, de acordo com o disposto no artigo 55 da Carta das Nações Unidas.

A partir dessa sistematização, tornou-se possivel, no plano internacional, por meio de tratados multilaterais, adotar-se medidas concretas de proteção aos direitos humanos.

2. Os julgamentos de Nuremberg e seu legado para o desenvolvimento da justiça internacional

Ao final da Segunda Guerra Mundial, com o colapso do regime nazista e a observação de abomináveis violações aos direitos humanos perpetrados por Hitler e seus seguidores, os Aliados, convictos da sua vitória sobre os países do Eixo, decidiram por julgar os principais líderes nazistas e as suas organizações e instituições.

"O Tribunal de Nuremberg, em 1945-1946, significou um poderoso impulso no processo de justicialização dos direitos humanos. Ao final da Segunda Guerra e após intensos debates sobre as formas de responsabilização dos alemães pela guerra e pelos bárbaros abusos do período, os aliados chegaram a um consenso, com o Acordo de Londres de 1945, pelo qual ficava convocado um Tribunal Militar Internacional para julgar os criminosos de guerra" (PIOVESAN, 2015, p. 77).

O Acordo de Londres definiu as normas aplicáveis aos processos e definiu os crimes que seriam julgados. Os réus foram acusados não só de terem exterminados milhões de pessoas, mas também por terem planejado e perpetuado a guerra pela Europa.

Observa-se que os julgamentos de Nuremberg combinaram elementos de common law e de direito romano germânico.

O Tribunal de Nuremberg, em 9 de dezembro de 1946, julgou vinte e três pessoas, vinte das quais médicos, que foram consideradas como criminosos de guerra, devido aos brutais experimentos realizados em seres humanos. O Tribu- 
nal demorou oito meses para julgá-los. Em 19 de agosto de 1947 o próprio Tribunal divulgou as sentenças, sendo que sete de morte, e um outro documento, que ficou conhecido como Código de Nuremberg. Este documento é um marco na história da humanidade, pois pela primeira vez foi estabelecida uma recomendação internacional sobre os aspectos éticos envolvidos na pesquisa em seres humanos.

Os julgamentos de Nuremberg julgaram e condenaram os criminosos nazistas pelos seguintes crimes:

a) Crime de genocidio;

Quando foi criado o tribunal de Nuremberg, ainda não estava em uso o termo genocídio, cunhado por um jurista polonês, Rafat Lemkin, em 1944, ao lançar nos Estados Unidos uma campanha de esclarecimento da opinião pública mundial sobre o massacre dos judeus poloneses. Mas a Assembleia Geral das Nações Unidas passou a utilizá-lo já em 1946, ao aprovar a sua Resolução 96 (I), datada de 11 de dezembro" (COMPARATO, 1999, p.224).

Genocídio significa a exterminação sistemática de pessoas tendo como principal motivação as diferenças de nacionalidade, raça, religião e, principalmente, diferenças étnicas. É uma prática que visa eliminar minorias étnicas em determinada região. A palavra genocídio é derivada do grego "genos" que significa "raça", "tribo" ou "nação" e do termo de raiz latina "cida" que significa "matar.

Em 27 de maio de 1915, como medida de guerra, o governo otomano decretou a deportação de toda a população armênia localizada na Anatólia oriental, sob a acusação de ligações com tropas inimigas que operavam no Cáucaso (COMPARATO, 1999, 222).

Outro caso de genocídio ocorrido no século XX se deu entre os anos 1932 e 1933 na ex URSS do governo de Stalin.

O Holodomor - "fome-extermínio" ou "assassinato pela fome" - teria ocorrido entre os anos de 1932 e 1933, na Revista do Curso de Direito da Faculdade de Humanidades e Direito, v. 14, n. 14, 2017 • 55 DOI: http://dx.doi.org/10.15603/2176-1094/rcd.v14n14p51-65 
Ucrânia, onde todos os estoques de alimentos dos agricultores ucranianos foram requisitados à força com o objetivo de eliminar a população de agricultores para favorecer as políticas de coletivização do governo soviético. Como resultado, estima-se que entre 7 a 10 milhões de pessoas tenham morrido de fome.

Durante o Nazismo houve uma banalização do ser humano como sujeito de direitos e todo o esforço na construção dos direitos humanos com as Declarações de Direitos do século XVIII foram perdidos.

Ainda de acordo com a Convenção para a prevenção e a repressão do crime de genocídio de 1948, o genocídio é tratado como:

Artigo I - As partes - contratantes confirmam que o genocídio, quer cometido em tempo de paz, quer em tempo de guerra, é um crime contra o Direito Internacional, o qual elas se comprometem a prevenir e a punir.

Artigo II - Na presente Convenção, entende-se por genocídio qualquer dos seguintes atos, cometidos com a intenção de destruir, no todo ou em parte, um grupo nacional, étnico, racial ou religioso, tal como: assassinato de membros do grupo; dano grave à integridade física ou mental de membros do grupo; submissão intencional do grupo a condições de existência que lhe ocasionem a destruição física total ou parcial; medidas destinadas a impedir os nascimentos no seio do grupo; transferência forçada de menores do grupo para outro.

\section{b) Crimes contra a humanidade;}

De acordo com o artigo 6.o, alínea c, do Estatuto do Tribunal Militar Internacional de Nuremberg, fazem parte da definição dos crimes contra a humanidade:

O assassínio, o extermínio, a redução à condição de escravo, a deportação e todo ato desumano, cometido contra a população civil antes ou depois da guerra, bem como as perseguições por motivos políticos e religiosos, quando tais atos ou perseguições, constituindo ou não uma violação do direito interno do país em 
que foram perpetrados, tenham sido cometidos em consequência de todo e qualquer crime sujeito à competência do tribunal, ou conexo com esse crime.

c) Crimes de guerra: configuram violações ao Direito Humanitário Internacional e ao Direito costumeiro da guerra. Essas violações incluem assassinato; tratamento cruel; deportação de populações civis; assassinato de reféns; destruição de vilas ou cidades, devastação injustificada por ordem militar, etc, conforme se verifica da liçaõ de Guerra:

O Direito Internacional Humanitário é uma disciplina que faz parte do Direito Internacional Público; todavia, por ser a sua abordagem peculiar e restrita e tendo a sua fundamentação axiológica direcionada à dignidade da pessoa humana, lhe é conferida uma autonomia de atuação em relação ao Direito Internacional. O foco do Direito Internacional Humanitário é a limitação dos meios e métodos utilizados durante o conflito. Entenda-se por meio o tipo de arma utilizada durante os atos de beligerância, enquanto o método significa a maneira de utilizar tal arma. (GUERRA, 2015, p. 48).

A convenção da ONU para a prevenção e a repressão do crime de genocídio de 1948 não impediu, não obstante os avanços que trouxe, novos massacres étnicos, como no caso dos muçulmanos bósnios mortos pela Sérvia nos anos 1990 ou a morte de mais de 800 mil pessoas em Ruanda, no conflito entre hutus e tutsis. Outras atrocidades também não puderam ser evitadas: os crimes cometidos durante as guerras da Coréia, do Camboja, no Oriente Médio, na Chechênia ou no Timor Leste.

3. Os Tribunais ad hoc dos anos 90 do século XX: preparação para a criação de uma corte criminal permanente Em 1991, após a queda do muro de Berlim, e o fim da guerra fria, teve início uma guerra na ex Iugoslávia. Em 1993 
a Bósnia sofreu ataque que partiu da Croácia. Os acontecimentos que deram origem aos conflitos na região foram graves crimes contra os direitos humanos:

As Guerras Iugoslavas ou Guerras dos Balcãs-também denominadas Guerras de Secessão Iugoslavas, dado o elevado número de países que proclamaram sua independência durante e após a guerra-, foram uma série de conflitos armados, na antiga Iugoslávia, que culminaram na morte de milhares de pessoas, e grave instabilidade política econômica nos países parte do combate, mesmo após o término do conflito. Foi considerada uma das crises humanitárias mais graves dos anos 90, com um alto saldo de morte, milhares de desaparecidos, e mais de 2 milhões de refugiados, que procuraram refúgio nos países vizinhos. (AQUINO, Valéria Emília de. ANDRADE, Juliana Demori de In: MENEZES, WAGNER, 2016, p.312).

Em 1992, a Resolução 780 do Conselho de Segurança da ONU solicitava que Boutros Boutros-Ghali, Secretário Geral na ocasião, formasse uma comissão de especialistas para analisar o caso dos conflitos na Iugoslávia. O relatório prévio da comissão, de 9 de fevereiro de 1993, levou o Conselho de Segurança a instituir provisoriamente um tribunal internacional.

Em 22 de fevereiro de 1993 foi criado pelo Conselho de Segurança da ONU, através da Resolução 808, um tribunal internacional ad hoc, o Tribunal Internacional para o Julgamento dos Crimes contra a Humanidade no Território da Antiga Iugoslávia, que teve seu estatuto redigido em 3 meses:

O Tribunal recebeu da ONU Jurisdição Internacional para processar e julgar especificadamente as pessoas físicas culpadas por violações à Convenção de Genebra, de 1949. Trata-se de violações às Convenções Internacionais sobre guerra e o costume internacional após o fim da Segunda Grande Guerra, crimes contra a Humanidade e genocídio, cometidos no território da ex-Iugoslávia, envolvendo terra, espaço aéreo e águas territoriais, com jurisdição temporal no período que começa em 
1.o de janeiro de 1991. O Tribunal Penal Internacional para a ex-Iugoslávia e as Cortes nacionais têm jurisdição simultânea para processar pessoas e, em caso de eventual conflito de competência, o Tribunal Internacional terá primazia. Em todo o estágio de procedimento acusatório, o Tribunal Internacional pode formalmente pedir cortes nacionais para remeter para sua competência" (MENEZES, 2013, p. 224).

O Tribunal Penal Internacional para a ex-Iugoslávia é um tribunal transitório, ad hoc, por isso mesmo criado com objetivos específicos e uma tarefa única: julgar um caso específico, e não há como negar que seu legado, sua contribuição, e em que pesem suas críticas, vão no sentido de lhe atribuir influência direta na criação do Tribunal Penal Internacional, o mesmo pode-se afirmar sobre o Tribunal Penal Internacional para Ruanda, também ad hoc.

Ruanda está localizada no continente africano, faz fronteira com Burundi, Uganda, Tanzânia e República Democrática do Congo. Sendo habitada por três etnias: hutu, tutsi e twa, sendo que o primeiro, é o grupo majoritário. Diferenças étnicas, políticas e econômicas, advindas da época da colonização fizeram com que as etnias hutu e tutsi iniciassem uma sangrenta guerra civil.

A criação do Tribunal Penal Internacional para Ruanda foi um instrumento necessário para o julgamento dos acusados de cometer o crime de genocídio no país. O Tribunal foi criado a partir da resolução $n^{\circ} 955$ da Organização das Nações Unidas em 8 de novembro de 1994:

Com sede em Arusha, na Tanzânia, o Tribunal para a Ruanda tem competência para julgar especificadamente pessoas individuais, quem planejou, instigou, requisitou, cometeu ou ajudou, participando do planejamento, na preparação ou na execução de um crime contra a Humanidade ou de Direito Humanitário, podendo ser os oficiais representantes do Estado ou responsáveis pelo governo, enfim qualquer pessoa que tiver comprovada sua participação nos atos ou que tivesse a possibilidade de 
impedir tais atos ou punir os seus executores" (MENEZES, 2013, p. 228).

4. O Tribunal Penal Internacional (TPI) e sua contribuição para o desenvolvimento dos direitos humanos do século XXI

O Tribunal Penal Internacional, ao contrário dos seus antecessores, mencionados no capítulo anterior, é uma instituição permanente, criada em 1998, por meio do Estatuto de Roma, e com sede em Haia, na Holanda. Conforme Piovesan:

Surgiu o Tribunal Penal Internacional como aparato complementar às Cortes nacionais, com objetivo de assegurar o fim da impunidade para os mais graves crimes internacionais, considerando que, por vezes, na ocorrência de tais crimes, as instituições nacionais se mostram falhas ou omissas na realização da justiça. Afirma-se, desse modo, a responsabilidade primária do Estado com relação ao julgamento de violações de direitos humanos, tendo a comunidade internacional a responsabilidade subsidiária. Vale dizer, a jurisdição do Tribunal Internacional é adicional e complementar à do Estado, ficando, pois, condicionada à incapacidade ou à omissão dos sistema judicial interno. O Estado tem, assim, o dever de exercer sua jurisdição penal contra os responsáveis por crimes internacionais, tendo a comunidade internacional a responsabilidade subsidiária. Como enuncia o artigo 1.o do Estatuto de Roma, a jurisdição do Tribunal é adicional e complementar à do Estado, ficando condicionada à incapacidade ou à omissão do sistema judicial interno. Dessa forma, o Estatuto busca equacionar a garantia do direito à justiça, o fim da impunidade e a soberania do Estado, à luz do princípio da complementariedade e do princípio da cooperação" (PIOVESAN, 2015, p.92).

De acordo com o artigo $5^{\circ}$ do Estatuto de Roma, que instituiu o Tribunal Penal Internacional, o Tribunal tem jurisdição sobre os crimes de genocídio, os crimes contra a humanidade, os crimes de guerra e os crimes de agressão, definidos respectivamente nos artigos 6, 7 e 8: 
Para os efeitos do presente Estatuto, entende-se por "genocídio", qualquer um dos atos que a seguir se enumeram, praticado com intenção de destruir, no todo ou em parte, um grupo nacional, étnico, racial ou religioso, enquanto tal:

a) Homicídio de membros do grupo;

b) Ofensas graves à integridade física ou mental de membros do grupo;

c) Sujeição intencional do grupo a condições de vida com vista a provocar a sua destruição física, total ou parcial;

d) Imposição de medidas destinadas a impedir nascimentos no seio do grupo;

e) Transferência, à força, de crianças do grupo para outro grupo.

O crime de genocídio teve o conteúdo da Convenção de Prevenção e Punição do Crime de Genocídio de 1948, incorporado ao anteprojeto do Estatuto do TPI.

Os crimes contra a humanidade, de acordo com o disposto no artigo 7.o do Estatuto, podem ser definidos como:

1. Para os efeitos do presente Estatuto, entende-se por "crime contra a humanidade", qualquer um dos atos seguintes, quando cometido no quadro de um ataque, generalizado ou sistemático, contra qualquer população civil, havendo conhecimento desse ataque:

a) Homicídio;

b) Exterminio;

c) Escravidão;

d) Deportação ou transferência forçada de uma população;

e) Prisão ou outra forma de privação da liberdade física grave, em violação das normas fundamentais de direito internacional; f) Tortura;

g) Agressão sexual, escravatura sexual, prostituição forçada, gravidez forçada, esterilização forçada ou qualquer outra forma de violência no campo sexual de gravidade comparável;

h) Perseguição de um grupo ou coletividade que possa ser identificado, por motivos políticos, raciais, nacionais, étnicos, culturais, religiosos ou de gênero, tal como definido no parágrafo $3^{\circ}$, ou em função de outros critérios universalmente reconhecidos como inaceitáveis no direito internacional, relacionados com 
qualquer ato referido neste parágrafo ou com qualquer crime da competência do Tribunal;

i) Desaparecimento forçado de pessoas;

j) Crime de apartheid;

k) Outros atos desumanos de caráter semelhante, que causem intencionalmente grande sofrimento, ou afetem gravemente a integridade física ou a saúde física ou mental.

No entanto, é importante frisar que a tipificação dos crimes de guerra não é pacífica entre os doutrinadores, sendo objeto de muita discordância entre os mesmos.

A origem histórica dos crimes contra a humanidade está ligada ao massacre provocado pelos turcos contra os armênios, na Primeira Guerra Mundial, tendo sido esta ocorrência qualificada pela Declaração do Império Otomano (feita pelos governos russo, francês e britânico, em maio de 1915, em Petrogrado) como um crime da Turquia contra a humanidade e a civilização.

Em relação aos crimes de guerra, são considerados parte do direito internacional costumeiro, e suas principais fontes são o Direito de Haia e as Convenções de Genebra com seus protocolos. O Estatuto de Roma assim os definem:

2. Para os efeitos do presente Estatuto, entende-se por "crimes de guerra":

a) As violações graves às Convenções de Genebra, de 12 de Agosto de 1949, a saber, qualquer um dos seguintes atos, dirigidos contra pessoas ou bens protegidos nos termos da Convenção de Genebra que for pertinente:

i) Homicídio doloso;

ii) Tortura ou outros tratamentos desumanos, incluindo as experiências biológicas;

iii) $\mathrm{O}$ ato de causar intencionalmente grande sofrimento ou ofensas graves à integridade física ou à saúde;

iv) Destruição ou a apropriação de bens em larga escala, quando não justificadas por quaisquer necessidades militares e executadas de forma ilegal e arbitrária; 
v) $\mathrm{O}$ ato de compelir um prisioneiro de guerra ou outra pessoa sob proteção a servir nas forças armadas de uma potência inimiga;

vi) Privação intencional de um prisioneiro de guerra ou de outra pessoa sob proteção do seu direito a um julgamento justo e imparcial;

vii) Deportação ou transferência ilegais, ou a privação ilegal de liberdade;

viii) Tomada de reféns;

Previsto pelo Estatuto de Roma, o crime de agressão, gerou grandes controvérsias para chegar a sua definição questionou-se até a sua própria inclusão no Estatuto. As discussões foram passadas aos trabalhos da Corte de Direito Internacional e ao Comitê Preparatório por três motivos em especial: a) ausência de um consenso sobre a definição do crime; b) a responsabilidade individual por crime de agressão em contraposição à ideia de guerra de agressão e consequente responsabilização do estado; c) e previsão da agressão no Capítulo VII da Carta das Nações Unidas como competência do Conselho de Segurança:

Até janeiro de 2014, oito situações foram, assim, submetidas à jurisdição do Tribunal Penal Internacional gerando 20 casos. Deste universo de situações: três foram submetidas pelos próprios Estados-partes (República Democrática do Congo, Uganda e República Centro Africana); três situações foram submetidas pelo Conselho de Segurança da ONU quanto a Estados não partes (Sudão e Líbia); e finalmente duas situações foram iniciadas de ofício pela Promotoria do Tribunal (Estados do Quênia, da Costa do Marfime de Mali) (PIOVESAN, 2015, p. 99).

Deve-se mencionar que o Brasil, por meio da Emenda Constitucional 45, instituiu o parágrafo 4.0 do artigo 5.o, da Constituição Federal, aceitando a jurisdição do Tribunal Penal Internacional e incorporando-a como direito fundamental. 


\section{CONSIDERAÇÕES FINAIS}

Observou-se que a criação do Tribunal de Nuremberg ad hoc- foi criado para julgar criminosos de guerra nazistas, e, em que pesem as críticas de não respeito ao princípio da legalidade, ser um tribunal de vencedores, onde não foram respeitados alguns princípios básicos de Direito Penal, no campo dos Direitos Humanos, os avanços foram notáveis, principalmente ao lançar as bases da formação do Direito Internacional Humanitário.

Ao longo das décadas, alguns outros tribunais ad hoc foram constituídos com a mesma finalidade do Tribunal de Nuremberg, contudo, com objetivos mais claros e coerentes com a normatização dos direitos humanos, por exemplo: a pena de morte dos julgamentos de Nuremberg foi substituída por penas mais brandas, no máximo, de prisão perpétua.

Nos anos 90 do século XX foram criados tribunais ad hoc a partir de demanda do Conselho de Segurança da ONU e da opinião pública internacional. É o caso do Tribunal Penal Internacional para a ex Iugoslávia e do Tribunal Internacional ad hoc para Ruanda.

Esses tribunais, seus princípios e fundamentos, foram decisivos para a criação de um tribunal verdadeiramente permanente, que congregasse a maior parte dos paises cientes da importância da criação de um órgão internacional jurisdicional internacional competente para julgar Estados e até mesmo pessoas fîsicas em situações de desacordo com a legislação internacional de direitos humanos, para esses fins, foi criado em 17 de julho de 1998, na Conferência de Roma, o Tribunal Penal Internacional.

\section{REFERENCIAS}

ACORDO DE LONDRES. Disponivel em: <http://www.dhnet.org.br/direitos/ anthist/nuremberg/nuremberg/anexo.html>, acesso em 18/09/2016. AQUINO, Valéria Emília de \& ANDRADE, Juliana Demori de. Tribunais penais internacionais: o caso Slobodan Milosevic e a manutenção da 
segurança internacional. In: MENEZES, WAGNER. Direito Internacional em expansão. Belo Horizonte: Arraes, 2016, v. IX, p. 311-322.

ARENDT, Hannah. Eichmann em Jerusalém. Um relato sobre a banalidade do mal. São Paulo: Companhia das Letras, 2006.

BRASIL Decreto $n^{\circ} 4.388$, de 25 de setembro de 2002. Promulga o Estatuto de Roma do Tribunal Penal Internacional <http://www.planalto.gov.br/ccivil_03/decreto/2002/D4388.htm>, acesso em 17/09/2016.

COMPARATO, Fábio Konder. A afirmação histórica dos direitos humanos. São Paulo: Saraiva, 1999.

CONVENÇÃO PARA A PREVENÇÃO E A REPRESSÃO DO CRIME DE GENOCÍCIO. Disponivel em: <http://www.dhnet.org.br/direitos/sip/onu/genocidio/ conv48.htm>, acesso em 27/09/2016.

GUERRA, Sidney. Direito Internacional dos Direitos Humanos. 2.a ed. São Paulo: Saraiva, 2015.

MAZZUOLI, Valério de Oliveira. Curso de Direito Internacional Público. 9.a ed. São Paulo: RT, 2015.

MENEZES, Wagner. Tribunais internacionais: jurisdição e competência. São Paulo: Saraiva, 2013.

PIOVESAN, Flávia. Direitos Humanos e Justiça Internacional. 6.a ed. São Paulo: Saraiva, 2015.

RAMOS. André de Carvalho. Teoria Geral dos Direitos Humanos na Ordem Internacional. 6.a ed. São Paulo: Saraiva, 2016.

REZEK, Francisco. Direito Internacional Público. 15.a ed. São Paulo: Saraiva, 2015. 